\section{A NOTE ON THREE SPECIES OF THE GENUS OLENECAMPTUS CHEVROLAT (COLEOPTERA: CERAMBYCIDAE: LAMIINAE) FOUND IN INDIA}

\section{H.V. Ghate and A. Sen}

Department of Zoology, Modern College, Shivajinagar, Pune, Maharashtra 411005, India

Email: hemantghate@hotmail.com

plus web supplement of 2 pages

The genus Olenecamptus Chevrolat, 1835 is included in the tribe Dorcaschematini Thomson. There are several species of Olenecamptus in India; the commonest and widespread species is Olenecamptus bilobus (Fabricius) which has many subspecies. Stebbing (1914) redescribed O. bilobus in detail and also commented on its life history. It appears that this is a pest of various species of figs (Ficus sp.). Stebbing (1914, page 375) also described the other species as "Olenecamptus sp. nov.", which is now known as $O$. anogeissi Gardner. Beeson (1941, pages 151 to 153) commented on six species of Olenecamptus from the various parts of British India with reference to their life cycles, and plants affected by those species.

During our recent collections of cerambycid beetles in Pune and nearby areas, we came across two different species of the genus, $O$. bilobus and $O$. anogeissi, both found in Pune and other parts of Maharashtra. A third species, O. signaticollis Heller (a single specimen collected from near Ponmudi, Kerala), was also available for comparison. We are presenting here a brief description, morphometry and a combined colour photograph of the three species (Image $1^{\mathrm{w}}$ and Table 1) along with brief comments on genitalia.

\section{Olenecamptus bilobus (Fabricius)}

Male: Body colour brown, with a pattern of bilaterally symmetrical white spots on the lateral side of the prothorax and dorsal side of the elytra, with adpressed grey-brown, white and dark brown pubescence. Front of face, clypeus, genae, bases of mandibles with dense white pubescence; sparse white pubescence at the base of mouthparts. Ventrally, whole body covered in dense snow-white pubescence leaving aside a few areas. Legs clothed with sparse white pubescence. Antennae clothed in pale straw coloured pubescence. Elytra with a large basal white pubescent patch bordered with brown pubescence, a small white patch just below the basal spot away from the suture on the lateral margin, also a medium oval patch at the $2 / 3^{\text {rd }}$ of elytra, all bordered with brown pubescence. In life, the large white spots on elytra are actually bright crimson and are lined with dark brown. These colours disappear with dry preservation and long storage.

Body slender. Head small, broad, impressed with a longitudinal line that covers the back of the head and reaches to the front. Frons with black, median slender carina that extends in length to the upper edge of clypeus. Eyes coarsely facetted, lower lobe larger than the upper (which comprises of only four rows of ommatidia), 5-6 coarse, black punctures lining the outer border of the upper lobe of eye, on either side of the vertex.

Antennae longer than body, slender. Antenniferous tubercles depressed in front, antennal sockets raised on the inner side in the vertex region. First antennomere (scape) swollen, stout, dorsally with coarse dark brown tubercles (Image $2^{\text {w }}$ ), ventrally with adpressed white pubescence, $2^{\text {nd }}$ antennomere disc-like, tuberculate, small with sparse white pubescence ventrally, $3^{\text {rd }}$ and $11^{\text {th }}$ antennomere the longest, $3^{\text {rd }}$ and $4^{\text {th }}$ antennomeres dorsally strongly asperate (more asperate in male than in the female), brown; $5^{\text {th }}$ to $11^{\text {th }}$ antennomeres more or less smooth but with many fine spinules ventrally in male (Image $3^{\mathrm{w}}$ ); $3^{\text {rd }}$ antennomere twice longer than $4^{\text {th }}, 4^{\text {th }}$ to $10^{\text {th }}$ almost equal in length.

Prothorax broader at the anterior margin, constricted near the base. Anterior margin lined with grey-brown pubescence. Disc with transverse wrinkles. On either side of the mid-line, at the base of prothorax, a small bilaterally symmetrical and pubescent patch, which is confluent with the latero-ventral pubescent pattern. Scutellum clothed in dense white pubescence, spade shaped, with two spots bare of pubescence on either side near the apex.

Elytra punctate, puncturation coarser at the humeral region. Humeral 'shoulder' devoid of pubescence. The puncturation of elytra finer towards the apices. Apices ending into a short blunt tubercle at the marginal angles. Punctures not visible on white pubescent bands and apical tip of elytra.

All legs compressed. Femora clavate. Tibiae slender with two ventral spines (tibial spurs). Prothoracic tibiae asperate beneath. $3^{\text {rd }}$ tarsal joint the longest, deeply bilobed. Claws diverge at $180^{\circ}$. Prothoracic legs longer than the rest. The distal tip of metathoracic femora not reaching the elytral apex.

Metepisterna narrow. Fore coxae angulated on the outer side. Ventral body clothed in dense, silver white pubescence. Hind breast bare of pubescence on either side forming two brown spots, bilaterally symmetrical at the lateral edge.

Genitalia: Tegmen 1.5mm in length, slender, curved. Parameres long and slender. Apical setae not very long; $0.1 \mathrm{~mm}$ in length (Total length of Paramere from the base $=0.3 \mathrm{~mm}$ ). Median lobe gently curved, apex truncate. Median struts short.

Female: In female the antennae are about two times longer than body but not as long as in the males (where these are more than twice the body-length). Antennae in female are also slightly slender than those in male; scape, $3^{\text {rd }}$ and $4^{\text {th }}$ antennomeres are less asperate.

The following two species are described only briefly. Common characters are not repeated.

${ }^{w}$ See Images 1-6 in the web supplement at www.zoosprint.org

(c) Zoo Outreach Organisation; www.zoosprint.org Manuscript 1580; Received 17 June 2006: Finally accepted 17 October 2006: Date of publication 21 November 2006 
Table 1. Morphometry of three species of Olenecamptus

\begin{tabular}{|c|c|c|c|c|c|c|c|c|}
\hline \multirow[t]{2}{*}{ Parameter } & \multicolumn{4}{|c|}{$\begin{array}{l}\text { Olenecamptus anogeissi } \\
\text { (specimen number in bold) }\end{array}$} & \multicolumn{3}{|c|}{$\begin{array}{c}\text { Olenecamptus bilobus } \\
\text { (specimen number in bold) }\end{array}$} & \multirow{2}{*}{$\begin{array}{l}\text { Olenecamptus } \\
\text { signaticollis } \\
1 \text { (female) }\end{array}$} \\
\hline & 1 (male) & 2 (male) & 3 (female) & 4 (female) & 1 (male) & 2 (male) & 3 (female) & \\
\hline TL & 16.2 & 17.5 & 15.0 & 12.5 & 17.2 & 14.0 & 10.3 & 14.0 \\
\hline HB & 3.6 & 3.8 & 3.4 & 2.8 & 3.8 & 3.2 & 2.2 & 3.0 \\
\hline PL & 3.5 & 4.0 & 2.8 & 2.3 & 3.2 & 2.6 & 1.9 & 2.7 \\
\hline PB & 2.5 & 2.5 & 2.4 & 1.9 & 2.7 & 2.4 & 1.7 & 2.3 \\
\hline AL & - & 40 & 30.4 & 28.1 & 40 & 39 & 29.5 & 25.0 \\
\hline
\end{tabular}

TL - total length; HB - breadth at humeral angle; PL - prothorax length; PB - prothorax breadth; AL - antenna length; - Data not available. All measurements in $\mathrm{mm}$

\section{Olenecamptus anogeissi Gardner}

Male: Colour red-brown. Body slender, with a bilaterally symmetrical pattern of spots and bands of snow-white pubescence on elytra. Two broad dorso lateral bands of white pubescence extending along the posterior margin of the inner lobe of the eye, down towards prothorax, slightly interrupted in the anterior and not reaching the posterior edge of the prothorax. Vertex clothed with thin pubescence excepting those bands. The face clothed in pale white pubescence. First three antennomeres darker in colour, rest of the antennomeres appear a shade lighter due to yellow pubescence, with their apices tinged dark brown.

Head with a black, longitudinal, fine median line. The anterior margin of prothorax lined with white pubescence. Basal margin dark brown to black. Prothorax with distinct fine transverse wrinkles. Scutellum semicircular, sparsely pubescent, with small depression distally where it meets the elytral suture. Apex of elytra angular with a dark tubercle like marginal spine. Punctures forming rows on both sides of the suture, whereas lateral sides with irregular, coarse punctures.

Femora clavate with distal half tinged black, clothed in dirty white pubescence. Ventrally body and legs evenly clothed in dirty white pubescence. Metasternum black or blackish. Apex of $1^{\text {st }}$ abdominal sternite blackish.

Antennae in male and female show similar differences as noted for $O$. bilobus. Male antennae are longer and distinctly more asperate than those of female (Images $4^{\mathrm{w}}, 5^{\mathrm{w}} \& 6^{\mathrm{w}}$ ).

Male genitalia: Tegmen $1.6 \mathrm{~mm}$ in length, slender, curved. Parameres almost parallel to eachother, long. Apical setae not half of the length of parameres. Median lobe $1.5 \mathrm{~mm}$ in length, gently curved from the lateral view. Median struts are short, not slender. The apex of Median lobe is truncate.

\section{Olenecamptus signaticollis Heller}

Female: Body colour brown, with a pattern of bilaterally symmetrical white pubescence on vertex, prothorax and elytra. Body clothed in tan pubescence; antennomeres with a golden yellow pubescence and black sparse pubescence at the apices of the terminal few antennomeres. Ventrally some area in front of prosternum devoid of pubescence, nitid; $11^{\text {th }}$ antennomere appearing dark brown to blackish due to black setae. Ventrally body yellow-brown, clothed with a golden yellow pubescence allover, like that on the front face. Abdominal sternites laterally marked with spots of dark brown pubescence.

Head impressed with a fine median line that is a slightly broader in the vertex region. Prothorax with light tan pubescence, broader at the anterior margin constricted just near the base, with transverse wavy depression / ridge. Disc of prothorax with many transverse wrinkles, especially in the middle. Prothorax with more or less 'A' shaped white pubescent patches, on either side of the middle of disc, almost bilaterally symmetrical; three very small, brown tubercles arranged diagonally, on either side of the midline, near the base.

Scutellum tongue shaped, with small adpressed white pubescence. Apex of elytra angulate with blunt marginal tubercle.

\section{Male genitalia}

There is no significant morphological difference in the genitalia of $O$. anogeissi and $O$. bilobus. However, we have compared the genitalia with diagrams of three different Russian species, viz., O. mordkovitshi Tshernyshev and Dubatolov, O. clarus Pascoe and O. octopustulatus (Motschulsky) (Tshernyshev and Dubatolov, 2000). It was apparent that in the Russian species tegmen is of different shape; the bases of parameres are more widely separated, the apex of median lobe (Ml) is more acute. The oedeagus is in fact much curved dorsally in $O$. mordkovitshi.

\section{REFERENCES}

Beeson, C.F.C. (1941). The Ecology and Control of the Forest Insects of India and neighbouring Countries. Govt. of India, 767pp. (1961 reprint).

Stebbing, E.P. (1914). Indian Forest Insects of Economic Importance. Eyre and Spottiswoode, London, 648pp.

Tshernyshev, S.E. and V.V. Dubatolov (2000). A new species of longhorn-beetle from East Siberia. Reichenbachia Staatliches Museum fur Tierkunde Dresden 33(49): 305-389.

\section{ACKNOWLEDGEMENTS}

The authors are indebted to Dr. Carolus Holzschuh, Austria, for his constant encouragement and for his help in identification of the cerambycid beetles of India. It would have been an impossible task to identify Lamiinae members, even common ones, up to species level, without his support. We are also grateful to the authorities of Modern College for the facilities provided.

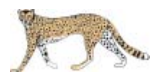

